\title{
MoBlogs, Sharing Situations and Lived Life
}

\author{
Connor Graham \\ Dept of Information Systems, \\ University of Melbourne \\ Parkville, Victoria 3010, \\ Australia \\ cgraham[at]unimelb.edu.au
}

\author{
Christine Satchell \\ Dept of Information Systems, \\ University of Melbourne \\ Parkville, Victoria 3010, \\ Australia \\ satc[at]unimelb.edu.au
}

\author{
Mark Rouncefield \\ Dept of Computing, Lancaster \\ University \\ InfoLab21, Lancaster, \\ Lancashire, England \\ m.rouncefield[at]lancs.ac.uk
}

\begin{abstract}
The generation and sharing of digital content is being transformed by new advances in mobile blogging technology. Here we wish to reflect on and review blogging and pervasive image capture and sharing practices reported on in literature to gain new insights for directions into future research of moblogging practices in the course of everyday lived life. Specifically we wish to stretch recently adopted rapid ethnographic approaches (i.e. probes) and the notion of 'digital document' to gain insights into how real time capture and seamless publishing and sharing of digital content in different kinds of places (domestic, work, thirdplace and civic) may: lead to a tighter coupling between 'blog-life' and real-life; augment existing physical communities; provide opportunities for sharing content via displays; sharpen (or blur) the differences between what particular technologies are used for; reduce editing of shared content; demand different metaphors for sharing content; increase awareness of self and others; and instigate more 'economical' interactions across different channels.
\end{abstract}

\section{Author Keywords}

Moblogging, pervasive image capture and sharing, blogging

\section{ACM Classification Keywords}

H5.m. Information interfaces and presentation (e.g., HCI): Miscellaneous.

\section{INTRODUCTION}

Bill Gaver and Tony Dunne [5], eloquently conjure a vision of Projected Realities: a networked system of electronic displays with which 'elders' in a large planned housing development just outside Amsterdam (the Bijmer) could share opinions and images over large areas. The vision described scanners and small mains radio devices embedded in the home supporting capture and display of "emotional content" along with "slogan furniture" and "image boards" positioned in the outdoor areas displaying provocative statements and value-laden images particular to the community:

"This network of electronic displays would project an increasingly coherent expression of the Bijmer, encouraging inhabitants to reflect on their own values, those of the diverse cultural groups sharing the district, and those of the surrounding culture. A nervous system for the Biljmer, it would help to provoke awareness of the existing community both to inhabitants and to the surrounding culture." [5:601]

In this paper and the research we plan, we wish to explore the possibilities that such "personal scanners", in this case new blogging technologies, afford not only the capture but also the sharing of digital content across different situations. In particular, we wish to review reported practices around blogging and pervasive image capture and sharing in order to gain insights into the detail of how Gaver and Dunne's vision might play out through personal technologies (e.g. mobile blogs, phone cameras) in both private and public settings (e.g. the home, 'third places' and public spaces). We plan to both leverage mobile blogs as purveyors of various digital 'documents of life' [15] in rapid ethnographic studies of people's lived experiences, and probe possible uses and candidate domains for moblog research. In doing so, we aim to explore the future potential design characteristics of and challenges posed by 'moblogs' which potentially result in a new type of mobile phone driven shared place where users can instantly upload content that is available for consumption across a variety of 'public' situations. We describe these in more detail below as domestic, work, third place and civic.

\section{APPROACH}

Our approach in this work to date has been to utilize personal use and experiences with a range of Nokia mobile phones (namely the N80 and N93) supporting mobile blogging software. We have also reviewed moblogging and aligned practices reported on in literature to develop insights and generate questions which we will pursue through more 'formal' rapid ethnographic enquiry later in our research. We report on our review of literature and personal experiences below. By adopting this approach, we 
acknowledge both the importance of researching technology-in-use and the importance of Plummer's [15:34] sentiments with regard to self-observation in social science research, written in Documents of Life:

"Somehow our scientific work is taken less seriously if it is known to be based on personal experience. Yet, given the argument of this book on the need to grasp subjective worlds, this method of self-documentation must be one of the most critical of all tools."

Beyond our initial inquiry reported on here we aim to stretch existing, if recent, social science research techniques - in particular 'cultural' probes, the use of photos, and technology probes. In doing so, we wish to explore the potential for moblogs to be and interface with a new breed of services which extend, converge and diverge across devices, in particular display technologies. Our particular interest is in probing the kinds of situations, and by implication, display (e.g. the television) and connecting (e.g. BlueTooth) technologies, that people might (want to) share digital content in. In doing so we so we suggest that moblogs are potentially 'socially translucent systems' [4], enabling people to draw upon their social experience and structure their interactions with each other through providing qualities such as visibility, awareness and accountability.

Both 'cultural' and 'technology' probes [6, 10] have already been used as 'inspirations' for design; and 'blogs' have been shown to provide rich detail about everyday social activity [13]. With moblogs Plummer's [15] 'miscellanea' are converged into one artefact: a person's very personal possession becomes a tool for selfobservation and potential technology probe [10] if deployed appropriately. The phones on which moblogs depend are both social and personal artifacts attached to the individual as they live their lives. Thus they present not only the opportunity to capture and gain insights into individuals' lives as they unfold across time (e.g. through time-stamping) and place (e.g. through images of places or "placestamping'), but also to potentially support social networks, connectedness to others and everyday work such as personal task management

A key underpinning commitment for us is the belief that the reflexivity, enforced by such approaches compels people to think about, write about and take pictures of aspects of their daily lives (e.g. places) they normally take for granted: 'fragmentary glimpses' that point to important technology design sensitivities. We are interested in the extent to which the mobile phone can afford this reflexivity and indeed become a form of "personal scanner" of everyday life - as well as facilitating and being married with other, more traditional research techniques such as interviewing. We wish to build on the notion of "mobile probe" [9] and use mobile phones to:

- Collect data about people's lives (moblog as cultural probe);
- Share data and act as support for future use situations (mobolog as prop);

- Act as a basis for future technology design (moblog as technology probe).

\section{BLOGS, PICS AND MOBLOGS}

This section presents a brief review of literature on blogging, pervasive image capture and sharing and moblogging. Our intent is on gaining insights into and refining questions we will explore through our research.

\section{Blogs}

Studies of blogging show three primary types of blogs: individually authored personal journals, "filters" (because they select and provide commentary on information from other websites), and "knowledge logs" and that the majority of blogs are the personal journal "online diary" type [8]. Indeed [13] discuss how blogging is a social activity beyond diary-keeping that can be used for a number of objects including: updating others, expressing opinions to influence others, seeking others' opinions and feedback, thinking through writing to an audience and the release of emotional tension. We agree with Nardi et al. [13] that the "the affordances of blogging are currently being worked out by millions of users, and tool-makers are adapting blog features to this use".

Blogs can have aspects of many other forms of personal documents [15:14-33]: they are part life history, part diary, part letter, part guerrilla journalism, part 'literature of fact' and they support multiple media elements, such as photographs, videos and voice recordings. Blogs, far from being overly individualistic, can reflect a group or community and its happenings from a humanized, contextualized and richly personal perspective [3].

\section{Pervasive Image Capture and Sharing}

The introduction of cameras into mobile phones has brought about new social practices. For example, when members of a social network cannot be together physically, images captured and shared in real time via mobile phones not only can provide an authentic way to share the experience, but also, ultimately, reinforce real life friendship networks and social connectedness [21]. As Ito [11] notes, the introduction of image capturing and sharing into the social stream brings with it a light weight visual communication, "an intimate visual co-presence", which ideally, acts as an extension of SMS.

Indeed, recent studies of mobile media have explored extensions of current technologies for sharing digital content (e.g. MMS) to support seamless sharing of media among groups. [17] describe MobShare, a mobile phone content sharing system that challenges the notion of the mobile phone as an artifact that facilitates only individual authorship of content by allowing for the management of images via shared digital albums within a social group. [12] describe how spectators can actively contribute to an event 
through a field study of a car rally. They utilize these insights in the development of mGroup, a content sharing mobile messaging system that converts "the mobile terminal into both a powerful means of expressing and learning supportive group experiences". This is achieved through: story-based content structure; automatic album creation for post-event retrospection; and support for communicating that group members are "there". Thus "the spectator' is re-imagined through the use of novel technologies, becoming an active participant in the creation of an event. [16] report on a messaging application, Media Stories, that supports the immediate, collective construction of a blog. They describe how Media Stories allowed users who are co-present at an event to have an enhanced feeling of "being there", creating a sense of "shared space".

Until recently, the spontaneous sharing of digital content via mobile phones has been one-to-one and, at most, peerto-peer exchanges (e.g. via MMS, Bluetooth, IR). However, new technologies such as Nokia's LifeBlog and Flickr, extend mobile phone image capturing and sharing capabilities beyond one-to-one sharing into more public networks (the Internet) creating public digital spaces which afford sharing and viewing of content.

\section{Moblogs}

Mobile blogging provides the opportunity to capture, store and share information not only based on time, but on many other aspects of situations, including place. Moblogs also permit the extension of personal social space [20] and the construction of a 'digital narrative' as it unfolds (through SMSes for example) that can, potentially, be shared and made public instantaneously (through a peer-to-peer network for example). Indeed, visions of blogging in the future extend to attaching digital memories to particular places that can be shared and act as a form of personal memorial after death [7]. A recently reported on prototype [2] exploits a hybrid architecture (peer-to-peer and clientserver), RFID tag readers in Wi-Fi enabled phones, and RFID tags in place to enable tagging of particular things in the real world (e.g. a restaurant). These entities can be commented on and 'read about' through mobile phone posting functionality via a central 'blog server'. This 'blog server' is used to store mappings between particular RFID tags and relevant posts. Individual clients (mobile phones) can access these postings through communication with the RFID tag and the server.

[1] describes a set of requirements for moblog clients emerging from a study of blogger's needs, including: the need for a mobile phone to converge blog and other phone functionality elegantly; the need for mobile blogging to integrate with other forms of blogging; the need to facilitate intuitive, seamless posting of images; the need to support management and editing tasks; the need to exploit cheap connectivity and manage broken connectivity transparently. $\mathrm{He}$ reports on a Symbian-based client that "provides a convenient, usable link between a mobile user, their immediate actions and thoughts, and the blog onto which they want to share things." An important additional function allowed users to develop user-define labels or "categories" allowing blog entries to be clustered and viewed according to topic, not only according to their temporality.

\section{INSIGHTS INTO MOBLOG PRACTICES}

John Urry in 'Sociology Beyond Societies' [19] argues for new research methods to take account of the diverse mobilities of peoples, objects, images, and information and their complex interdependencies. This suggests that when carefully placed and shared across particular settings moblogs can become poignant accounts of unfolding events that, in turn, unfold with events and indeed, become hyperreal accounts of real-life events. Indeed the moblog, like a biography, has the opportunity to capture a subjective account of the ever-changing, constantly evolving relationship between individuals as they traverse different places and share experiences with others. We are interested in investigating these issues through leveraging the 'digital documents of life' generated via moblogs. We believe that certain issues have largely been neglected in research to date: how moblogs are used, what the consequences of moblog use are (e.g. in terms of changed practices), how moblogs can be extended and what moblogs are good for. The following insights regarding moblogs have been generated from our investigations addressing these issues.

\section{Tightness of coupling with everyday life}

Although digital in nature, the real time capture and sharing facilities of mobile blogs mean they are tightly coupled with the user's everyday life. These temporal changes offer an immediacy of shared experiences that can potentially transform the very nature of blogging from a reflective narrative of past events, to the real-time disclosure of activity supporting 'social translucence' [4]. Users' reactions to this changing paradigm will be important to explore.

\section{A hyperreal extension of physical communities}

Traditional blogging communities share the traits of virtual communities where members are dispersed geographically and are unknown to each other in real life. On the other hand, content sharing via mobile phones is an extension of social or community groups who have real life interactions. What are the implications of making the 'walled garden' nature of content sharing public through moblogs?

\section{The potential use for shared physical displays}

Gaver and Dunne [5] constrain their use of display technologies to civic situations and are not specific concerning how generated digital content would be selected for display. As mobile blogging sees the personal becomes public, there is a need for an enhanced understanding of 'public' situations where people share and 'consume' digital content across devices. Broadly, we categorise these settings as domestic, work, 'third place' and civic. 'Third 
place' draws on Oldenberg's [14] notion of a space between work and the home - social spaces, such as cafes and bars, where anonymous company is enjoyed and conversation flows. Civic settings are locales [18] in an urban environment that are less social than public and converged on by various 'social worlds' [18].

The figure below shows a domestic setting where 'digital memories' are shared via shuffling images on an artefact with that has been domesticated: the television.

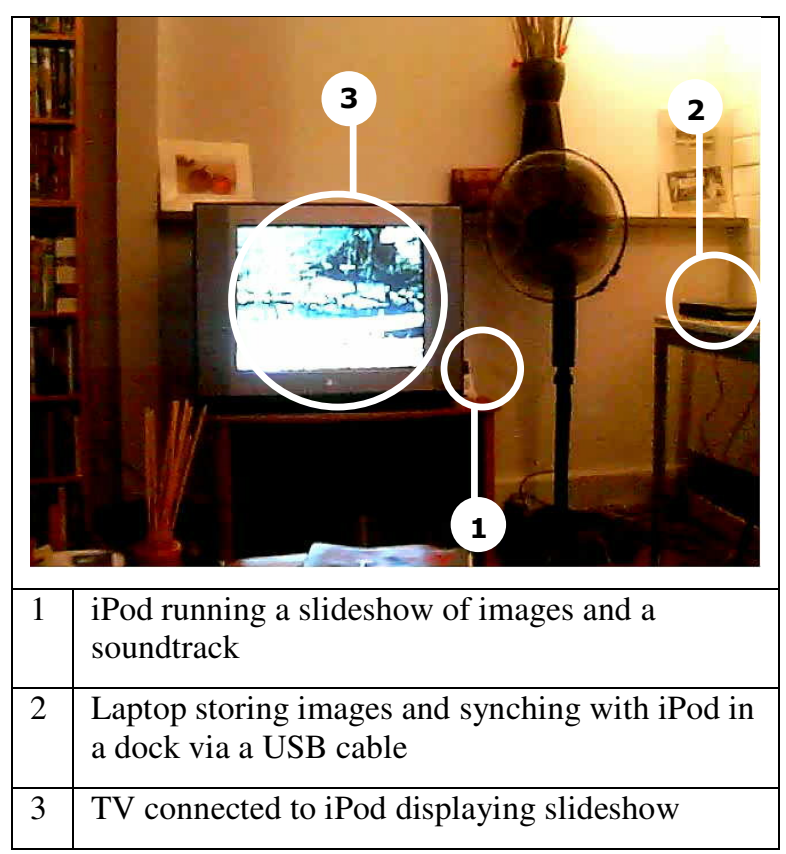

Figure 1. Possible configuration of technology sharing moblog content in the home.

Understanding the possible technology configurations in and movements among these kinds of settings is important.

\section{Heightened differences in affordances of artefacts}

Everyday life can potentially be captured and displayed almost instantaneously through moblogs, heightening the differences between what a mobile phone affords (through e.g. a inbuilt camera) and what even a highly portable laptop affords: the phone becomes even more personal and proximal to life as it unfolds and personal computers support more deliberative interaction through e.g. display and editing of photos. These affordances are important to investigate as users embed technology into the organization that is already there in their lives through, potentially, meshing blogging practices and technologies with photo capture and storage practices and technologies.

\section{Reduced editorial voice}

The spontaneity afforded by a moblog posting means the presentation is more organic than a traditional blog which is generally an account of an activity distributed after the event via a computer. Especially with digital images, content is often highly edited, enhanced, and mashed. Will the instantaneousness of moblogging erode not only the editorial process but also the creativity that characterizes traditional blog spaces and content sharing practices?

\section{Non-temporal metaphors of storytelling}

Currently, much blogging and moblogging software uses time as the organizing principle for digital content. What possibilities exist to both automatically and manually 'markup' digital content to support sharing and organization through e.g. capture of cell information and user-generated labels [1] respectively?

\section{Awareness of self and others}

The 'real time' nature of mobile blogging postings has the potential to provide a continual update of what the user is 'doing now', thus affording greater awareness of others' presence. This could increase ad-hoc physical interactions: revealing current activities to other members of a social group may give serendipity a nudge, increasing the chances of ad hoc physical encounters. Will users engage with mobile blogging to create a digital representation of their identity in way that changes the way they come together in physical space?

\section{More economical interaction}

Moblogging may reduce gratuitous mobile interaction across different channels-providing information about current activity could reduce unnecessary phone calls and SMSes made purely to establish presence and availability. On a practical level, it could be seen that sharing digital images potentially provided a quicker and more user friendly means of forming maintaining social contact than e.g. SMSes would: "Once the visual stream enters this shared virtual space, it can lessen the volume of text exchange" [11:3]

\section{CONCLUSION}

In this paper we have described our position on how we believe practices around moblog generation and sharing across different places can be investigated through 'digital documents of life' and some of the insights we have gained through our preliminary investigations. Our research aims to generate the following outputs:

\section{More detailed insights into 'sharing situations'}

We will 'flesh out' (through scenarios for example) and, indeed, evaluate, 'sharing situations' across domestic, work, 'third place' and civic settings through examining how people mesh and converge technologies e.g. mobile phone cameras, moblogs, the Internet.

\section{Candidate domains for further research}

We will carefully consider problem spaces where different kinds of sharing might have positive impact, or at least warrant further research e.g. tourism (e.g. sharing traveling experiences with intimates as they happen), life change (e.g. getting support for giving up smoking), raising awareness to socio-political issues (e.g. ethical consumption of 
products), 'guerrilla journalism' through enabling the moblogger to become a form of vox populi, creating personal 'news' outside the broadcast paradigm (cf. Current TV - http://www.currenttv.com/, You Tube http://www.youtube.com/).

\section{Methodological insights}

We recognize that the mobile phone is in itself, a culturally loaded artefact and its introduction into peoples' lives as a form of probe requires critical reflection. One concern is that the use of a mobile phone blog as a probe potentially turns the participant into an 'instant celebrity' through documenting his/her life. Unlike traditional research where the data is hidden in a drawer, the detail of participants' lives can be broadcast live to the Internet, should s/he wish. This may have consequences. Could a participant terminate a potentially unwanted digital identity that was generated by participating in the study for? What are the digital consequences of someone's 'real' identity shifting? Another concern is that introducing mobile probes into an established physical community potentially provides a hyperreal account of the group's actions and interactions. What is the potential for this new digital element to alienate people in the group? What are the consequences of no longer supporting moblogging practices in the community e.g. when the technology is no longer supported after the research?

\section{ACKNOWLEDGMENTS}

This research was funded by a Nokia University Donation (Mobile Phones as Probes, Props and Prototypes For Life Change) and Microsoft Research European Fellowship (Social Interaction and Mundane Technologies).

\section{REFERENCES}

1. Beale, R. Mobile Blogging: Experiences of Technologically Inspired Design. Ext. Abstracts CHI 2006 , ACM Press (2006), 225-230

2. Cheng, Y. M., Yu, W. and Chou, T. Z. Life is Sharable: Blogging Life Experience with RFID Embedded Mobile Phones. In Proc. Mobile HCI 2005, ACM Press, 295-298.

3. Cheverst, K., Conder, C., Graham, C. and Rouncefield, M.. Scarecrow Ethnography. Ethnography Conference, 13-14 ${ }^{\text {th }}$ September 2006, The University of Liverpool.

4. Erickson, T., Kellogg, W. Social Translucence - An Approach to Designing Systems that Support Social Processes. ACM Transactions in Computer-Human Interaction 7, 2000, 59-83.

5. Gaver, W. and Dunne, A. Projected Realities. In Proc. CHI 1999, ACM Press (1999), 600-607.

6. Gaver, W., Dunne, A., Pacenti, E. Design: Cultural Probes. Interactions: New Visions of Human-Computer Interaction 6, 1 (1999), 21-29.

7. Hall, A. and Bosevski, D. and Larkin, R. Blogging by the Dead. In Proc. NordiCHI 2006, ACM Press (2006), 425428.
8. Herring, S., Scheidt, L., Bonus, S. and Wright, E. Bridging The Gap: A Genre Analysis Of Weblogs. In Proc. HICSS 2004. IEEE Press (2004).

9. Hulkko, S., Mattelmäki, T.; Virtanen, K. and Keinonen, T., Mobile Probes. In Proc. NordiCHI 2004, ACM Press (2004), 43-51.

10. Hutchinson, H., Mackay, W., Westerlund, B., Bederson, B.B, Druin, A., Plaisant, C., Beaudouin-Lafon, M., Conversy, S., Evans, H., Hansen, H., Roussel, N. and Eiderbäck, B. Technology probes: Inspiring Design for and with Families. In Proc. CHI 2003, ACM Press (2003), 1724.

11. Ito, M. Intimate Visual Co-Presence. Ubicomp 2005 Workshop. Pervasive Image Capture and Sharing: New Social Practices and Implications for Technology, 2005.

12. Jacucci, G., Oulasvirta, A., Salovaara, A., and Sarvas, R. Supporting the Shared Experience of Spectators through Mobile Group Media. In Proc. GROUP 2005, ACM Press (2005), 207-216.

13. Nardi, B. A., Schiano, D. J., and Gumbrecht, M. Blogging as Social Activity, or, Would you Let 900 Million People Read Your Diary? In Proc. CSCW 2004, ACM Press (2004), 222-231.

14. Oldenberg, R. The Great Good Place: Cafés, Coffee Shops, Community Centers, Beauty Parlors, General Stores, Bars, Hangouts, and How They Get You Through The Day. Paragon House: New York, 1989.

15. Plummer, K. Documents of Life. George Allen \& Unwin: London, 1983.

16. Salovaara, A., Jacucci, G., Oulasvirta, A., Saari, T., Kanerva, P., Kurvinen, E., and Tiitta, S. Collective Creation and Sense-Making of Mobile Media. In Proc. CHI 2006, ACM Press (2006), 1211-1220.

17. Sarvas, R., Viikari, M., Pesonen, J., and Nevanlinna, H. MobShare: Controlled and Immediate Sharing of Mobile Images. In Proc. Multimedia 2004, ACM Press (2004), 724-731.

18. Strauss, A. Life Styles and Urban Space. In Proshansky, H.M., Ittelson, W.H. \& Rivlin, L.G., (eds) Environmental Psychology: People and Their Physical Settings. Holt, Rinehart \& Winston: New York, 1976.

19. Urry, J. Sociology Beyond Societies: Mobilities for the Twenty-first Century. Routledge: London and New York, 2000.

20. Wang, Hsiu-Chuan, Yi-Shin Deng, and Sean Chiu. Beyond Photoblogging: New Directions of Mobile Communication. In Proc. Mobile HCI 2005, ACM Press (2005), 341-342

21. Van House, N. A., Davis, M., Ames, M., Finn, M., and Viswanathan, V. The Uses of Personal Networked Digital Imaging: An Empirical Study of Cameraphone Photos and Sharing. Ext. Abstracts CHI 2005, ACM Press (2005), 1853-1856 
